\title{
COMMENTARY
}

\section{In vivo and in vitro evidence for pleiotropic effects of levosimendan in the intensive care setting}

\author{
Mehmet Birhan Yilmaz and Alexandre Mebazaa2* \\ See related research by Hasslacher et al., http://ccforum.com/content/15/4/R166
}

\begin{abstract}
Levosimendan, in addition to its inotropic properties, could have anti-inflammatory and anti-oxidative properties, and can potentially decrease the deleterious effects of reactive oxygen species on the tissues. In their study, Hasslacher and colleagues provided not only in vitro but also in vivo evidence that levosimendan could preserve organ function in acute heart failure and septic-shock-induced myocardial depression via cooling down the oxidative burst of circulating cells.
\end{abstract}

Hasslacher and colleagues have provided a new piece of data regarding pleiotropic effects of levosimendan [1]. In their elegantly designed study, the authors showed in both in vitro and in vivo experiments that levosimendan 'cools down' oxidative burst in polymorphonuclear neutrophils, and hence prevents or decreases the deleterious effects of reactive oxygen species.

Levosimendan is known not only to be an inodilator but also to exert cellular protective effects by antioxidant, anti-inflammatory, anti-apoptotic properties [2-4]. Herein, the authors seem to puzzle out one piece of the whole pathophysiologic mechanism driving septic-shockinduced myocardial dysfunction. Interesting enough, in patients with septic shock, oxidative burst activity was cooled down in unstimulated as well as in stimulated polymorphonuclear neutrophils, whereas in patients with acute heart failure only stimulated oxidative burst was cooled down by levosimendan. We think that the clinical meaning of such a differential effect deserves to be investigated in future studies. It is possible to turn such net improvements into clinically meaningful benefit

*Correspondence: alexandre.mebazaa@lrb.aphp.fr

2Department of Anesthesiology and Critical Care Medicine, Hospital Lariboisière,

APHP, Université Paris Diderot Paris 7, U942 Inserm Paris, France

Full list of author information is available at the end of the article providing that the time, route and mode of administration are well controlled.

Decreased respiratory burst activity of polymorphonuclear neutrophils in the study could possibly be driven by the membrane hyperpolarizing effect of levosimendan or phosphodiesterase III inhibitory effects, which is mainly observed at high doses. Actually, measuring plasma levels of levosimendan could have been helpful in understanding which mechanism dominated. Whatever the mechanism, such an effect should be kept in mind to tailor the therapy of patients suffering from potentially hazardous complications of excess reactive oxygen species including septic shock. Of note, upon preload optimization by fluid administration and/or vasopressor treatment in the study, levosimendan treatment seemed to be well accepted by the patients. However, the reason for the lack of a relationship between a decrease in oxidative burst and survival might be linked to the time of initiation of drug administration. Inotropic therapy is usually considered a last option in many patients, and oxidative burst could possibly have already done its irreversible injury in such patients. We think the present study provides a unique opportunity to move faster in decision-making and therapy.

\section{Competing interests}

AM received honorarium for lectures from Orion Pharma. MBY declares no competing interests.

\section{Author details}

'Cumhuriyet University School of Medicine, Department of Cardiology, Sivas, Turkey. ${ }^{2}$ Department of Anesthesiology and Critical Care Medicine, Hospital Lariboisière, APHP, Université Paris Diderot Paris 7, U942 Inserm Paris, France.

\section{Published: 18 August 2011}

\section{References}

1. Hasslacher J, Bijuklic K, Bertocchi C, Kountchev J, Bellmann R, Dunzendorfer S, Joannidis M: Levosimendan inhibits release of reactive oxygen species in polymorphonuclear neutrophils in vitro and in patients with acute heart failure and septic shock: a prospective observational study. Crit Care 2011, 15:R166.

2. Parissis JT, Andreadou I, Bistola V, Paraskevaidis I, Filippatos G, Kremastinos DT: Novel biologic mechanisms of levosimendan and its effect on the failing heart. Expert Opin Investig Drugs 2008, 17:1143-1150.

3. Zager RA, Johnson AC, Lund S, Hanson SY, Abrass CK: Levosimendan protects against experimental endotoxemic acute renal failure. Am J Physiol Renal Physiol 2006, 290:F1453-F1462. 
4. Adamopoulos S, Parissis JT, lliodromitis EK, Paraskevaidis I, Tsiapras D, Farmakis D, Karatzas D, Gheorghiade M, Filippatos GS, Kremastinos DT: Effects of levosimendan versus dobutamine on inflammatory and apoptotic pathways in acutely decompensated chronic heart failure. Am J Cardiol 2006, 98:102-106

\section{doi:10.1186/cc10308}

Cite this article as: Yilmaz MB, Mebazaa A: In vivo and in vitro evidence for pleiotropic effects of levosimendan in the intensive care setting. Critical Care 2011, 15:182 